\title{
Alterations in hepatic one-carbon metabolism and related pathways following a high-fat dietary intervention
}

\author{
Citation for published version (APA): \\ Rubio-Aliaga, I., de Roos, B., Sailer, M., McLoughlin, G. A., Boekschoten, M. V., van Erk, M., Bachmair, \\ E. M., van Schothorst, E. M., Keijer, J., Coort, S. L. M., Evelo, C. T. A., Gibney, M. J., Daniel, H., Muller, \\ M., Kleemann, R., \& Brennan, L. (2011). Alterations in hepatic one-carbon metabolism and related \\ pathways following a high-fat dietary intervention. Physiological genomics, 43(8), 408-416. \\ https://doi.org/10.1152/physiolgenomics.00179.2010
}

\section{Document status and date: \\ Published: 01/01/2011}

DOI:

10.1152/physiolgenomics.00179.2010

\section{Document Version:}

Publisher's PDF, also known as Version of record

\section{Document license:}

Taverne

Please check the document version of this publication:

- A submitted manuscript is the version of the article upon submission and before peer-review. There can be important differences between the submitted version and the official published version of record. People interested in the research are advised to contact the author for the final version of the publication, or visit the DOI to the publisher's website.

- The final author version and the galley proof are versions of the publication after peer review.

- The final published version features the final layout of the paper including the volume, issue and page numbers.

Link to publication

\footnotetext{
General rights rights.

- You may freely distribute the URL identifying the publication in the public portal. please follow below link for the End User Agreement:

www.umlib.nl/taverne-license

Take down policy

If you believe that this document breaches copyright please contact us at:

repository@maastrichtuniversity.nl

providing details and we will investigate your claim.
}

Copyright and moral rights for the publications made accessible in the public portal are retained by the authors and/or other copyright owners and it is a condition of accessing publications that users recognise and abide by the legal requirements associated with these

- Users may download and print one copy of any publication from the public portal for the purpose of private study or research.

- You may not further distribute the material or use it for any profit-making activity or commercial gain

If the publication is distributed under the terms of Article $25 \mathrm{fa}$ of the Dutch Copyright Act, indicated by the "Taverne" license above, 


\title{
Alterations in hepatic one-carbon metabolism and related pathways following
} a high-fat dietary intervention

\author{
Isabel Rubio-Aliaga, ${ }^{1}$ Baukje de Roos, ${ }^{2}$ Manuela Sailer, ${ }^{1}$ Gerard A. McLoughlin, ${ }^{3}$ Mark V. Boekschoten, ${ }^{4,5}$ \\ Marjan van Erk, ${ }^{6}$ Eva-Maria Bachmair, ${ }^{2}$ Evert M. van Schothorst, ${ }^{7}$ Jaap Keijer, ${ }^{7}$ Susan L. Coort, ${ }^{8}$ \\ Chris Evelo, ${ }^{8}$ Michael J. Gibney, ${ }^{3}$ Hannelore Daniel, ${ }^{1}$ Michael Muller, ${ }^{4}$ Robert Kleemann, ${ }^{9}$ \\ and Lorraine Brennan ${ }^{3}$ \\ ${ }^{1}$ Molecular Nutrition Unit, ZIEL-Research Center for Nutrition and Food Sciences, Technische Universität München, \\ Freising-Weihenstephan, Germany; ${ }^{2}$ Rowett Institute of Nutrition and Health, University of Aberdeen, Aberdeen, UK; ${ }^{3} U C D$ \\ Institute of Food and Health, University College Dublin, Dublin, Ireland; and ${ }^{4}$ Netherlands Nutrigenomics Centre, TI Food \\ and Nutrition and ${ }^{5}$ Division of Human Nutrition, Wageningen University, Wageningen; ${ }^{6}$ Physiological Genomics team, BU \\ Biosciences, TNO-Quality of Life, Zeist; ${ }^{7}$ Human and Animal Physiology, Wageningen University, Wageningen; ${ }^{8}$ Department \\ of Bioinformatics, BiGCaT, Maastricht University, Maastricht; and ${ }^{9}$ Department of Vascular and Metabolic Diseases, \\ TNO-Quality of Life, Leiden, The Netherlands
}

Submitted 9 September 2010; accepted in final form 31 January 2011

Rubio-Aliaga I, de Roos B, Sailer M, McLoughlin GA, Boekschoten MV, van Erk M, Bachmair EM, van Schothorst EM, Keijer J, Coort SL, Evelo C, Gibney MJ, Daniel H, Muller M, Kleemann R, Brennan L. Alterations in hepatic one-carbon metabolism and related pathways following a high-fat dietary intervention. Physiol Genomics 43: 408-416, 2011. First published February 8, 2011; doi:10.1152/physiolgenomics.00179.2010.-Obesity frequently leads to insulin resistance and the development of hepatic steatosis. To characterize the molecular changes that promote hepatic steatosis, transcriptomics, proteomics, and metabolomics technologies were applied to liver samples from C57BL/6J mice obtained from two independent intervention trials. After $12 \mathrm{wk}$ of high-fat feeding the animals became obese, hyperglycemic, and insulin resistant, had elevated levels of blood cholesterol and VLDL, and developed hepatic steatosis. Nutrigenomic analysis revealed alterations of key metabolites and enzyme transcript levels of hepatic one-carbon metabolism and related pathways. The hepatic oxidative capacity and the lipid milieu were significantly altered, which may play a key role in the development of insulin resistance. Additionally, high choline levels were observed after the high-fat diet. Previous studies have linked choline levels with insulin resistance and hepatic steatosis in conjunction with changes of certain metabolites and enzyme levels of onecarbon metabolism. The present results suggest that the coupling of high levels of choline and low levels of methionine plays an important role in the development of insulin resistance and liver steatosis. In conclusion, the complexities of the alterations induced by high-fat feeding are multifactorial, indicating that the interplay between several metabolic pathways is responsible for the pathological consequences.

high-fat feeding; obesity; Kennedy pathway

OBESITY IS NOW CONSIDERED a major global health problem, and it is well recognized that it plays a central role in insulin resistance, the metabolic syndrome, and type 2 diabetes mellitus (T2DM). Expansion of adipose tissue is associated with changes in the levels of inflammatory cytokines $(2,6,51)$ and has most recently been linked as well to endoplasmic reticulum stress (15). Although increased hepatic accumulation of lipids

Address for reprint requests and other correspondence: L. Brennan, UCD Inst. of Food and Health, UCD Conway Inst., University College Dublin, Dublin, Ireland (e-mail: lorraine.brennan@ucd.ie). during obesity development is observed in rodents and humans, the underlying mechanisms are still not fully understood.

Diet is an important environmental factor in the development of obesity, and an imbalance of calorie intake and expenditure leads to weight gain. Because of the complex etiology and pathogenesis of obesity, animal models are valuable tools for deepening our understanding of human diseases in a controlled environment. For many years animal models have been used to study diet-induced obesity by feeding high-energy diets such as high-sucrose, high-fat, and cafeteria diets. One of the most commonly used models is the C57BL/6J mouse, which develops many pathological features like those in humans including visceral fatness, insulin resistance, hyperinsulinemia, and hyperlipidemia (19) but also hepatic steatosis in the course of increased triglyceride accumulation.

The amount of triglyceride present in the liver represents a complex interplay between hepatic uptake of free fatty acids from the plasma, de novo fatty acid synthesis, fatty acid oxidation, and triglyceride export as part of very low-density lipoproteins (VLDL). Many studies have shown that high-fat diets increase the expression of genes that promote lipid storage in rodents $(29,38)$. More recent studies using tracer compounds in vivo have shown that high-fat feeding induced hepatic fatty acid synthesis by chain elongation and subsequent desaturation as opposed to de novo synthesis (33). In rats it was demonstrated that the contribution of de novo lipogenesis to hepatic triglyceride contents is small when animals are fed a high-fat diet (10). To investigate how the progression of liver steatosis and the development of insulin resistance are promoted by fat accumulation, we used a nutrigenomic approach (employing metabolomics, transcriptomics, and proteomics) in an integrated multicenter study. Analysis of these multilayer data sets was hypothesized to enable a more comprehensive understanding of the hepatic alterations caused by fat storage. Biological samples were collected from two intervention studies performed in two centers as part of the collaborative research activities of the European Nutrigenomics Organisation (NuGO; www.nugo.org) Proof of Principle Study Package (NuGO PPS). The NuGO PPS contained three animal studies as described previously (3); here we report findings from the PPS2 and PPS3 studies. Both studies were performed 
with the same diets and had similar design, sampling, and analysis strategies with standard operation procedures defined by NuGO. Moreover, both studies were designed to have a common time point, namely 12 wk after low- and high-fat feeding. In the present study, analysis of the nutrigenomic data led to the identification of novel links between a high-fat diet and altered one-carbon metabolism.

\section{MATERIALS AND METHODS}

Animal studies. Within the federated package of NuGO two animal studies were conducted under very similar conditions (3) at the TNO-Quality of Life site in Leiden and at Wageningen University. All animals received humane care according to the criteria outlined in the Guide for the Care and Use of Laboratory Animals prepared by the National Academy of Sciences and published by the National Institutes of Health (NIH). All animal experiments were approved by an independent institutional ethical committee on animal care and experimentation, PPS2 by the Dierethische Commissie (DEC; Zeist, The Netherlands) with the study number DEC2465 and PPS3 by the Local Committee for Care and Use of Laboratory Animals at Wageningen University with the study number 2007118.b. In both studies male C57BL/6J mice were obtained at the age of $3 \mathrm{wk}$ and housed in wire-topped Macrolon cages with ad libitum access to food and water, and during the intervention phase the same diet and sampling protocol was applied. Two diets were administered to the animals: a high-fat diet and a low-fat diet, in which $45 \%$ and $10 \%$ of the energy were obtained from fat, respectively. Refined palm oil was the main fat source in the diets. Low-fat and high-fat diet compositions are specified in Supplemental Table S1 and were based on Research Diets formulas (www.researchdiets.com; D12450B, D12451). ${ }^{1}$ To balance the energy intake, the amount of corn starch was modified accordingly. Body weight and food intake were measured weekly during the intervention phase.

In PPS2, mice were purchased from Charles River (Maastricht, The Netherlands). At $10 \mathrm{wk}$ of age, animals were subjected to a 2-wk run-in on the low-fat diet specified above. At $12 \mathrm{wk}$ of age, the animals were randomized into two groups $(n=47 /$ group $)$ : the high-fat and the low-fat group. During experimental diet feeding, tail blood samples were obtained after $5 \mathrm{~h}$ of fasting from $8 \mathrm{AM}$ to $1 \mathrm{PM}$ at weeks $0,4,8$, and 12 to monitor glucose and insulin levels. After 12 wk of dietary treatment seven animals per group were used for monitoring the development of insulin resistance with a glucose tolerance test (GTT). After a defined fasting period ( $5 \mathrm{~h}$; from $8 \mathrm{AM}$ to $1 \mathrm{PM}$ ) the animals received a single intraperitoneal injection of glucose ( $2 \mathrm{~g} / \mathrm{kg}$ body wt). Blood samples were obtained at $0,20,40$, 60,120 , and $180 \mathrm{~min}$. The remaining 40 mice per group were randomized into five groups $(n=8)$ to study the dynamic changes within organs during a GTT. To this end, the animals followed the same GTT protocol as the monitor mice and were killed at five defined time points, namely, $0,0.6,2,18$, and $48 \mathrm{~h}$ after glucose injection. The data from the $0 \mathrm{~h}$ time point only are reported here. Mice were euthanized with $\mathrm{CO} / \mathrm{CO}_{2}$ according to the local ethics recommendations, and organs were collected. During euthanasia, blood was collected by heart puncture to prepare serum (centrifugation of clotted blood at 6,000 rpm for $10 \mathrm{~min}$ ).

In PPS3, mice were purchased from Charles River. At 12 wk of age all mice received a low-fat diet, in which $10 \%$ energy was obtained from fat, as a run-in for $4 \mathrm{wk}$. After the run-in period, mice were randomly divided into four weight-matched groups, which received four different diets with four increasing $(10 \%, 20 \%, 30 \%, 45 \%)$ amounts of fat ( $n=12$ /group). The diets used in PPS 2 and PPS3 were identical and from one batch provided by Research Diets. Plasma

\footnotetext{
${ }^{1}$ Supplemental Material for this article is available online at the Journal
} website. samples were taken by orbital puncture every 2 wk. After 12 wk mice were fasted for $5 \mathrm{~h}$ (from $8 \mathrm{AM}$ to $1 \mathrm{PM}$ ) and subsequently anesthetized with a mixture of isoflurane $(1.5 \%)$, nitrous oxide $(70 \%)$, and oxygen $(30 \%)$ according to the local ethics recommendations. Blood was collected by orbital puncture, after which the mice were killed by cervical dislocation. Only the data from the high-fat and low-fat groups after 12-wk intervention are reported here. In both studies, for RNA isolation and proteome and metabolome analysis the liver was excised, divided into five lobes, and snap frozen in liquid nitrogen.

Clinical chemistry parameters in blood. In PPS2, blood glucose levels were measured by the glucose hexokinase method (Instruchemie, Delfzij, The Netherlands). Insulin was measured with a Mercodia ELISA (Mercodia, Uppsala, Sweden). Cholesterol and triglycerides were measured as previously described (22). Serum folate was measured with a microbiological assay as previously described (31). Serum total homocysteine was measured by fluorescence polarization with an Abbott IMX instrument (Abbott) (27). In PPS3, blood glucose was measured after death with an Accu-Chek glucose meter (Roche Diagnostics, Almere, The Netherlands).

Amino acid analysis. The amino acids in liver and plasma were analyzed with the iTRAQ methodology from Applied Biosystems. For liver amino acids, frozen liver samples were homogenized with a mortar and pestle. One hundred milligrams of homogenized tissue was dissolved in $150 \mu \mathrm{l}$ of $\mathrm{H}_{2} \mathrm{O}-\mathrm{MeOH}$ (50:50), vortexed, and centrifuged. Forty microliters of the supernatant or forty microliters of plasma was used to label the amino acids with the AA45/32 Starter Kit according to the manufacturer's instructions (Applied Biosystems, Foster City, CA) and analyzed via liquid chromatography-tandem mass spectrometry (LC-MS/MS) (3200QTRAP LC/MS/MS, Applied Biosystems). The data were analyzed with Analyst 1.5 software. Liver amino acid concentrations were normalized with the protein concentration, which was determined with the Bradford assay.

Glutathione assay in liver tissue. A glutathione detection kit (Abcam, Cambridge, UK) was used to determine reduced (GSH), oxidized (GSSG) and total glutathione levels in liver tissue samples. Forty milligrams of each liver tissue sample was homogenized with $100 \mu \mathrm{l}$ of ice-cold glutathione assay buffer. Sixty microliters of the homogenate was transferred to a prechilled tube containing perchloric acid and vortex mixed for several seconds to achieve a uniform emulsion. Samples were kept on ice for $5 \mathrm{~min}$ and centrifuged for 2 $\min$ at $13,500 \mathrm{rpm}$ at $4^{\circ} \mathrm{C}$. The supernatant (containing glutathione) was collected and stored at $-80^{\circ} \mathrm{C}$. The amount of protein in the pellet was determined with a BCA Protein Assay Kit (Thermo Scientific Pierce, Cramlington, UK). GSH and GSSG were measured according to the manufacturer's instructions and based on the reaction of $o$-phthalaldehyde with GSH.

Triglycerides and total phospholipids in liver. Frozen liver samples were homogenized with a mortar and pestle, and triglycerides were determined after enzymatic hydrolysis with lipases and the Triglycerides liquicolor ${ }^{\text {mono }}$ kit (HUMAN, Wiesbaden, Germany). Total phospholipids were assayed with the commercial LabAssay Phospholipid kit (Wako Chemicals, Neuss, Germany). In brief, liver tissue was homogenized with liquid nitrogen and then dissolved in $300 \mu \mathrm{l}$ of $0.9 \% \mathrm{NaCl}$. The samples were constantly shaken for $10 \mathrm{~min}$ and afterwards centrifuged at $4^{\circ} \mathrm{C}$ for $30 \mathrm{~min}$. Twenty microliters of the obtained supernatant were used to run the assay. Triglycerides and total phospholipids were normalized with protein concentration, which was determined by Bradford assay.

Selected phospholipids and acylcarnitines in liver tissue. Lipids were extracted with $60 \mu \mathrm{l}$ of methanol per $10 \mathrm{mg}$ of homogenized liver tissue. The samples were vortexed and centrifuged, and $10 \mu \mathrm{l}$ of the supernatant was used for the assay. Acylcarnitines, phosphatidylcholines, and sphingolipids were analyzed with the AbsoluteIDQ kit (Biocrates Life Sciences) according to the manufacturer's instructions and with the 3200 QTrap-MS using MRM pairs. Samples were delivered to the mass spectrometer by the flow injection analysis 
method. Metabolite concentrations were normalized with the protein concentration, which was determined by Bradford assay.

Transcriptome analysis. Established protocols reported in detail recently (23) were used for RNA extraction, RNA quality control, microarray analysis, and microarray quality control were followed. Briefly, total RNA was extracted in PPS2 with RNAzol (Campro Scientific, Veenendaal, The Netherlands) and glass beads and in PPS3 with TRIzol reagent (Invitrogen, Carlsbad, CA), treated with DNase, and purified on columns with the RNeasy Mini Kit (Qiagen, Venlo, The Netherlands). The integrity of each RNA sample obtained was examined by Agilent Lab-on-a-chip technology using the RNA 6000 Nano LabChip kit and a Bioanalyzer 2100 (Agilent Technologies, Amstelveen, The Netherlands), and the quality of RNA preparations of PPS 2 and PPS3 were comparable. RNA preparations were considered suitable for array hybridization only if samples showed intact $18 \mathrm{~S}$ and 28S rRNA bands and displayed no chromosomal peaks or RNA degradation products (RNA integrity number $>8.0$ ). Microarray analysis was carried out with an Affymetrix technology platform and NuGO Affymetrix Mouse GeneChip arrays (NuGO_Mm1a520177) containing 23,865 probe sets, including 73 control probe sets. The NuGO arrays are custom-designed Affymetrix GeneChip arrays designed by NuGO and manufactured by Affymetrix. These arrays contain in part common probe sets that are also present on standard Affymetrix arrays and in part newly designed probe sets (http://www.bigcat.unimaas.nl/ $\sim$ martijn/NuGO/annotations/index.html). Briefly, fragmented cRNA was mixed with spiked controls and applied to Affymetrix Test chips, and good-quality samples were then used to hybridize with NuGO Affymetrix Mouse GeneChip arrays. The hybridization, probe array washing and staining, and washing procedures were executed as previously described (23), and probe arrays were scanned with a Hewlett-Packard Gene Array Scanner in PPS2 (Leiden Genome Technology Center, Leiden, The Netherlands) and with an Affymetrix GeneChip 3000 7G scanner in PPS3.

Quality control of microarray data was performed with Bioconductor packages (13), including simpleaffy and affyplm, through the NuGO pipeline that is available as a Genepattern procedure on http://nbx2.nugo.org (9). Probe sets were redefined according to Dai et al. (8) with remapped CDF version 11.0.2 based on the Entrez Gene database. The Nugo Mouse GeneChip arrays target 15,240 unique gene identifiers. GC-robust multiarray (GCRMA) analysis was used to obtain expression values (50). Only genes that had an unlogged intensity above 5 on at least five arrays of a group were considered for analysis. This criterion was met by 12,863 genes in PPS2 and 7,486 genes in PPS3. LIMMA was used to identify differentially expressed genes (40). Obtained $P$ values were corrected for multiple testing with a false discovery rate (FDR) method (43).

Proteome analysis. The frozen liver samples were homogenized with a mortar and pestle. One hundred milligrams of homogenate was resuspended in $1 \mathrm{ml}$ of lysis buffer [7 $\mathrm{M}$ urea, $2 \mathrm{M}$ thiourea, 2\% 3-[(3-cholamidopropyl)dimethylammonio]-1-propanesulfonate (CHAPS), $1 \%$ DTT, Complete Mini proteinase inhibitor], and the protein concentration was determined by the Bradford method. Two-dimensional gel electrophoresis was performed as described previously (14), with slight modifications. In brief, isoelectric focusing was performed on 18-cm immobilized $\mathrm{pH}$ gradient (IPG) strips (pH 3-10, GE Healthcare, Uppsala, Sweden). IPG strips were passively rehydrated in 350 $\mu \mathrm{l}$ of solubilization buffer for $8 \mathrm{~h}$, loading $350 \mu \mathrm{g}$ of protein with rehydration buffer containing $7 \mathrm{M}$ urea, $2 \mathrm{M}$ thiourea, 4\% CHAPS, $2 \%$ Pharmalyte $3-10$, and an additional $15 \mu$ l of $30 \%$ DTT. The second dimension was performed with $12.5 \%$ SDS-polyacrylamide gels. The gels were run overnight at $20^{\circ} \mathrm{C}$ and constant amperage, fixed, and stained with Coomassie blue. Gels were analyzed with Decodon Delta 2D software 4.0 (Decodon, Greifswald, Germany). Expression of the different protein spots was expressed as volume percentage (\%vol). Tryptic digestion of regulated protein spots and peptide mass fingerprinting by matrix-assisted laser desorption/ ionization time-of-flight mass spectrometry (MALDI-TOF-MS) were performed as described previously (49).

Metabolite extraction from liver tissue for NMR and GC-MS analysis. Aqueous and organic metabolites were extracted from liver tissue. Briefly, $\sim 100 \mathrm{mg}$ of frozen tissue was homogenized in a 1:2 mixture of chloroform and methanol $(600 \mu \mathrm{l})$. Samples were then sonicated three times on ice for $5 \mathrm{~s}$. Six hundred microliters of chloroform-water (1:1) was added, and the mixture was vortexed thoroughly. Samples were left to stand for $15 \mathrm{~min}$ before centrifugation at 13,500 rpm for $20 \mathrm{~min}$. The aqueous layer was dried under nitrogen gas and stored before NMR spectroscopy. The organic layer was combined with $20 \mu \mathrm{l}$ of $2 \mathrm{mg} / \mathrm{ml}$ pentadecanoic acid (C15:0) as an internal standard and then dried under nitrogen gas. Dried organic extracts were derivatized by methylation; $1 \mathrm{ml}$ of methanolic $\mathrm{BF}_{3}$ was added, and samples were incubated at $100^{\circ} \mathrm{C}$ for $45 \mathrm{~min}$. Samples were then dried under nitrogen gas and stored before GC-MS analysis.

NMR spectroscopy. Dried liver tissue aqueous extracts were prepared for NMR spectroscopic analysis by the addition of $550 \mu \mathrm{l}$ of $\mathrm{D}_{2} \mathrm{O}$ and $10 \mu \mathrm{l}$ of trimethylsilyl propionate (TSP). Spectra were acquired on a 600-MHz Varian NMR spectrometer (Varian, Oxford, UK) using a Noesypresat pulse sequence at $25^{\circ} \mathrm{C}$. Spectra were acquired with $32 \mathrm{~K}$ data points and 128 scans over a spectral width of $9.6 \mathrm{kHz}$. Water suppression was achieved during the relaxation delay $(1.5 \mathrm{~s})$ and the mixing time $(100 \mathrm{~ms})$. Serum samples were prepared by the addition of $10 \mu \mathrm{l}$ of TSP and $\mathrm{D}_{2} \mathrm{O}$ to a total volume of $550 \mu \mathrm{l}$. Spectra were acquired with a Carr-Purcell-Meiboom-Gill (CPMG) pulse sequence with $32 \mathrm{~K}$ data points and 64 scans over a spectral width of $9.6 \mathrm{kHz}$. Water suppression was achieved during the relaxation delay $(3 \mathrm{~s})$ and the mixing time $(100 \mathrm{~ms})$.

All ${ }^{1} \mathrm{H}$ NMR spectra were referenced to TSP at $0.0 \mathrm{ppm}$ and then phased and baseline corrected [initially with automated spectral processing software (Chenomx 6.0, Chenomx, Edmonton, Canada) and then manually where necessary]. A line-broadening factor of $0.2 \mathrm{~Hz}$ was also applied to all spectra. Chenomx 6.0 was also used for all spectra to calculate the integral of bins that consisted of spectral regions of $0.02 \mathrm{ppm}$. Bins from the water region of the spectra $(4.5-5.5 \mathrm{ppm})$ were then excluded before the data were normalized to the sum of the spectral integral for each spectrum.

$G C-M S$. Dried derivatives were resuspended in $200 \mu l$ of hexane and analyzed on an Agilent 7890A GC coupled with a 5975C MS with an Agilent HP-5ms $30 \mathrm{~m} \times 250 \mu \mathrm{m} \times 0.25 \mu \mathrm{m}$ column (Agilent, Santa Clara, CA). One microliter of the sample was injected in splitless mode, and the initial oven temperature of $70^{\circ} \mathrm{C}$ was raised to $220^{\circ} \mathrm{C}$ at $5^{\circ} \mathrm{C} / \mathrm{min}$, held for $20 \mathrm{~min}$, and then raised to $320^{\circ} \mathrm{C}$ at $20^{\circ} \mathrm{C} / \mathrm{min}$. Helium was used as the carrier gas with a flow of 1.2 $\mathrm{ml} / \mathrm{min}$. Calibration was achieved by comparison of peak areas for fatty acids with reference to a known standard (Supelco 37 compound mix, Supelco, Poole, UK) using Agilent Chemstation MSD E.02.00.493 and by comparison of their mass spectra with those in the NIST Library 2.0 (2005). Automatic peak detection was carried out with Agilent Chemstation mass spectral deconvolution (MSD). MSD was performed with AMDIS version 2.65. Peaks with a signal-to-noise ratio lower than 30 were rejected. To obtain accurate peak areas for the internal standard and specific peaks/compounds, one quant mass for each peak was specified as a target, and three masses were selected as qualifiers. Each data file was manually analyzed for false positives/negatives with Agilent Chemstation. The concentrations reported are percent fatty acids.

Data analysis and visualization. Initial data analysis of NMR data was performed with principal components analysis (PCA) and partial least-squares discriminant analysis (PLS-DA). Once discriminating metabolites were identified, a targeted analysis was performed with Chenomx software. NMR data were imported into SIMCA-P (version 11, Umetrics, Umea, Sweden), mean centred, and Pareto scaled $(1 / \sqrt{ } \mathrm{SD})$. Each data set (liver and serum) was analyzed with PCA, and the score plots were visually inspected for clustering trends and outliers. PLS-DA was then applied to the data sets, with diet as a 


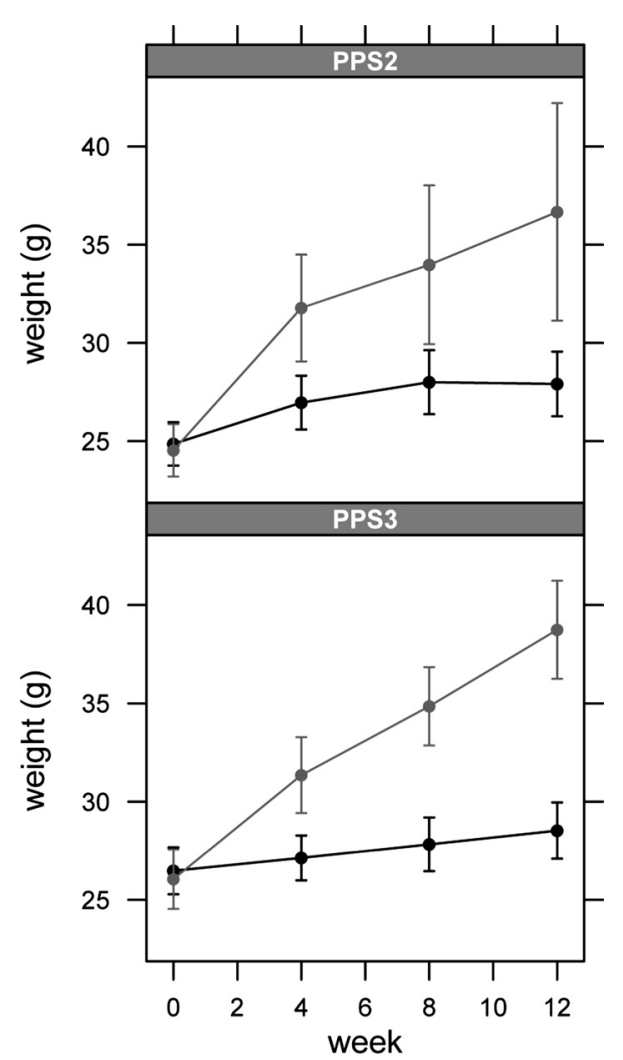

Fig. 1. Body weight development of mice under a low-fat (black) and a high-fat (gray) diet during 12-wk intervention. Data are represented as means \pm SD. PPS2, PPS3, Proof of Principle Studies 2 and 3.

classifier. Validation of metabolites and the GC-MS-derived fatty acid data and comparison between GSH and GSSG levels in liver tissue were performed in SPSS-V14 (SPSS) with one-way analysis of variance. Significance was assumed when $P$ value $<0.05$.

Data analyses of the remaining parameters were performed with the $\mathrm{R}$ software package (36). The different groups were compared by Student's $t$-test, and $P$ values were adjusted for multiple testing with the p.adjust function and the Benjamini and Hochberg method (4). Significance was assumed when $P$ value $<0.05$. The packages Hmisc (17), plyr (47), and reshape (48) were used for data transformation. Transcriptome, proteome, and metabolome data were visualized with PathVisio (45).

\section{RESULTS}

Development of liver steatosis and insulin resistance under a high-fat feeding regimen. After $12 \mathrm{wk}$ of intervention with a high-fat diet, the animals showed a significant body weight increase (Fig. 1), became hyperglycemic, and showed a three- fold increase in fasting insulin levels compared with control animals on a low-fat diet (Table 1). Additionally, plasma cholesterol increased significantly in the high-fat diet group. Total liver triglycerides were significantly increased in the animals fed a high-fat diet, whereas plasma triglyceride levels showed no statistically significant difference between the groups (Table 1). Food intake was similar on both diets, with a marginally higher intake for the low-fat diet [PPS3: no significant differences; PPS2: $3.30 \pm 0.14$ vs. $3.12 \pm 0.12$ $\mathrm{g} /$ day for low- and high-fat diets, respectively $(P=0.032)]$. GTT performed after $12 \mathrm{wk}$ in the monitor animals in PPS2 confirmed that the animals on the high-fat diet became glucose intolerant. After the high-fat diet mice had a significantly greater area under the glucose curve $[3,729 \pm 1,346$ vs. $6,295 \pm 1,170$ arbitrary units (au); $P<0.01]$, indicating insulin resistance in these mice. Additionally, the HOMA score was significantly higher in animals after the high-fat diet $(2.37 \pm 1.61$ vs. $0.55 \pm 0.28 ; P<0.005)$.

Metabolite and transcript levels identify one-carbon metabolism and related pathways as significantly changed in liver. NMR, LC-MS/MS, and enzymatic analyses revealed that a number of liver metabolites were significantly different between the dietary groups: among these metabolites those related to one-carbon metabolism and phospholipid handling were found to be overrepresented (Fig. 2; an interactive version of Fig. 2 in which fold changes are visible is available at http://137.120.17.30/, username: pathways, password: !pathways!). Methionine, serine, glycine, ethanolamine, and phosphoethanolamine concentrations were significantly decreased, whereas choline, taurine, and sarcosine concentrations increased significantly in animals fed the high-fat diet. Liver glutathione levels were altered: the oxidized form (GSSG) was increased whereas the reduced form (GSH) decreased after treatment with a high-fat diet. Data from gene expression analysis revealed that in the same samples changes in mRNA levels coding for proteins in pathways related to one-carbon metabolism occurred (Fig. 2). High-fat diets led in both feeding trials to increased transcript levels of Shmt1, Shmt2, Dmgdh, Bhmt2, Chpt1, and Gpx7, whereas Cbs and Cdol transcript levels decreased. Additionally, the PPS2 data showed Dnmt3a, glutathione-related genes (Gclc and Gsr), and genes (Cept1 and Pemt1) involved in phospholipid metabolism with reduced expression states, whereas Chkb, Matla, and Baat mRNA increased. In PPS3 decreased levels of Mat2a and Csad transcripts were observed, whereas $D h f r$ of the folate cycle was increased. Proteome analysis revealed that 46 spots showed differential intensities between $12 \mathrm{wk}$ of high-fat or control diet

Table 1. Altered parameters in mice after 12-wk high-fat diet intake

\begin{tabular}{|c|c|c|c|c|}
\hline Parameter & Low Fat PPS2 $(n=8)$ & High Fat PPS2 $(n=8)$ & Low Fat PPS3 $(n=12)$ & High Fat PPS3 $(n=12)$ \\
\hline Body weight, g & $27.91 \pm 1.65$ & $37.35 \pm 5.50 \neq$ & $28.53 \pm 1.53$ & $38.74 \pm 2.49 \ddagger$ \\
\hline Blood glucose, $\mathrm{mM}$ & $9.49 \pm 2.03$ & $16.05 \pm 2.33 \ddagger$ & $10.93 \pm 1.05$ & $1.13 \pm 0.65$ \\
\hline Plasma insulin, $\mathrm{ng} / \mathrm{ml}$ & $1.29 \pm 0.62$ & $3.68 \pm 1.98 *$ & nd & nd \\
\hline Plasma cholesterol, $\mathrm{mM}$ & $2.69 \pm 0.34$ & $4.02 \pm 0.99 *$ & nd & nd \\
\hline Plasma triglycerides, $\mathrm{mM}$ & $0.51 \pm 0.13$ & $0.45 \pm 0.05$ & nd & nd \\
\hline Liver triglycerides, $\%$ & $100 \pm 28.5$ & $197.0 \pm 50.8 *$ & $100 \pm 28.5$ & $176.2 \pm 50.3 \dagger$ \\
\hline
\end{tabular}

Values are represented as means \pm SD for $n$ animals. Low-fat and high-fat diets, diets in which $10 \%$ and $45 \%$ energy is provided by fat, respectively; PPS 2 and PPS3, Proof of Principal Studies 2 and 3, respectively, described in MATERIALS AND METHODS. Statistical analysis was performed by comparing high-fat diet to low-fat diet groups within the studies. Statistical significance: ${ }^{*} P<0.01, \dagger P<0.001, \ddagger P<0.0001$. nd, No data measured. 


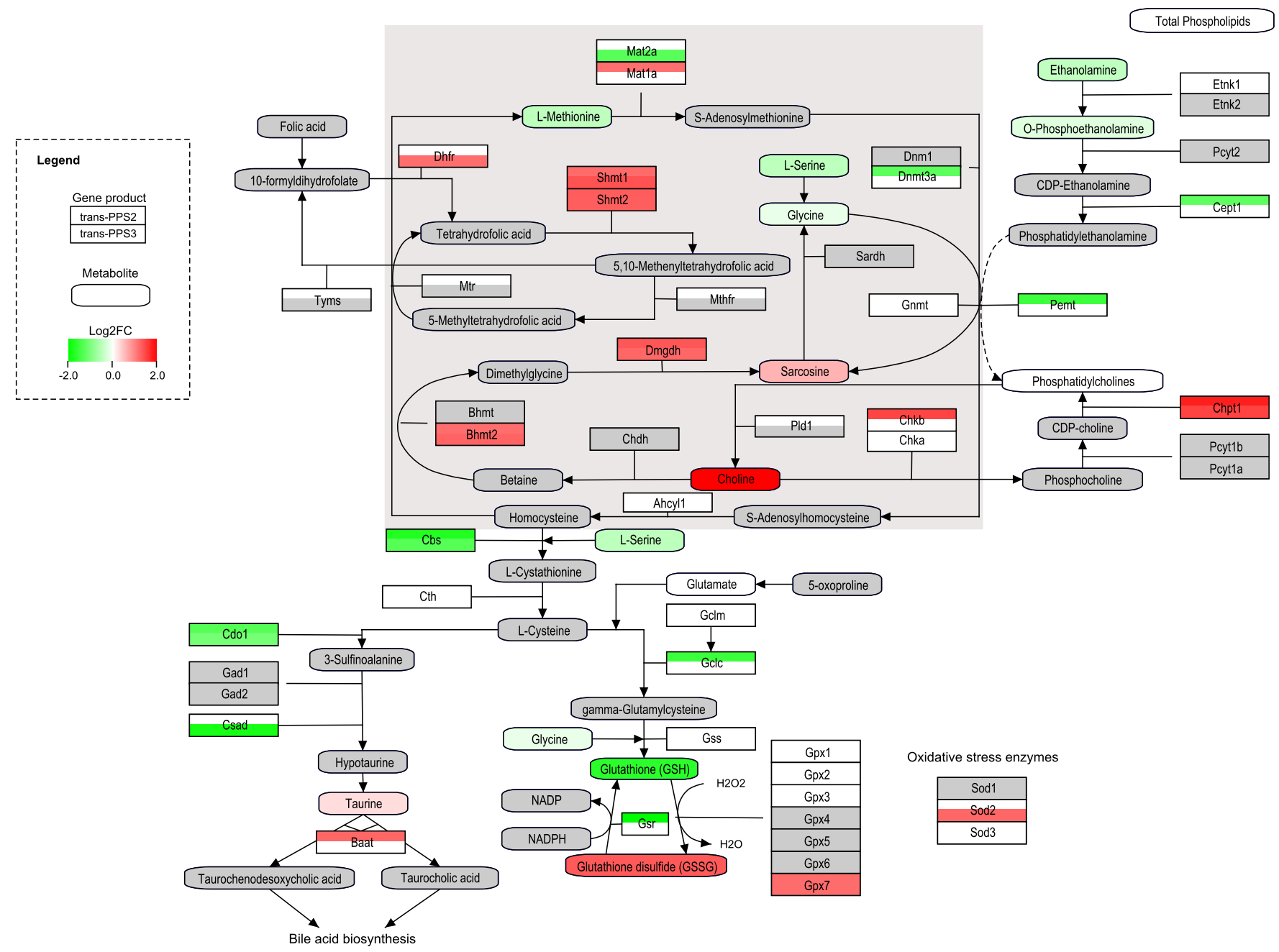

Fig. 2. Visualization of transcriptome and metabolome data in one-carbon metabolism and related pathways. Genes or metabolites not measured appear in gray; all others are as indicated in the key. The following experiments are depicted: transcriptome data from PPS2 (trans-PPS2), transcriptome data from PPS3 (trans-PPS3), and metabolome data. The high-fat diet vs. control diet base $2 \log$ fold change $\left(\log _{2} \mathrm{FC}\right)$ is depicted in white if there is no significant regulation $(P>0.05)$. Red color gradient indicates upregulation with $\log _{2} \mathrm{FC}>0$, and green color gradient indicates downregulation with $\log _{2} \mathrm{FC}<0$.

feeding. From these, 36 proteins were identified. However, none of these proteins was related to one-carbon metabolism.

Total phospholipids measured in the liver were not significantly altered $(60.90 \pm 29.01$ and $68.19 \pm 36.98 \mathrm{mg} / \mathrm{g}$ protein for low and high fat, respectively; $P=0.74$ ). However, LC-MS/MS analysis of 21 acylcarnitines, 72 phosphatidylcholines, 9 lysophosphatidylcholines, and 15 sphingomyelins revealed that 24 of these 117 metabolites changed significantly after $12 \mathrm{wk}$ of high-fat feeding. The changes occurred mainly in phosphatidylcholines containing long-chain polyunsaturated fatty acids with an ester or ether bond as well as three sphingomyelins and two lysophosphatidylcholines (Table 2). After the high-fat feeding the concentrations of a number of fatty acids were significantly changed in the liver (11 of 27 measured, Table 3 ). The total monounsaturated fatty acids increased, and n-3 polyunsaturated fatty acids including C20: $5 \mathrm{n} 3$ and $\mathrm{C} 22: 6 \mathrm{n} 3$ decreased.

Related one-carbon metabolite changes in plasma. Plasma amino acids related to one-carbon metabolism and related pathways were determined in PPS3. After 12 wk of high-fat feeding glycine, serine, cystine, phosphoethanolamine, methi- onine, and taurine showed similar levels in the animals fed either control or high-fat diet (data not shown). Ethanolamine was significantly increased in plasma of animals fed a high-fat $\operatorname{diet}(12.41 \pm 1.23$ and $14.32 \pm 1.23 \mu \mathrm{mol} / \mathrm{l}$ for low- and high-fat diets, respectively; $P=0.03$ ).

In PPS2, serum homocysteine concentrations were not significantly different between the groups $(7.4 \pm 1.2$ and $6.6 \pm$ $0.7 \mu \mathrm{mol} / \mathrm{l}$ for low and high fat, respectively). Serum folate concentrations did not change significantly after the high-fat diet $(41.4 \pm 4.2$ and $43.8 \pm 5.0 \mathrm{ng} / \mathrm{ml}$ in low- and high-fat groups, respectively). However, serum VLDL concentrations were significantly increased in animals on the high-fat diet (30.4 \pm 2.7 and $39.0 \pm 4.3$ au in low- and high-fat groups, respectively; $P<0.001$ ).

\section{DISCUSSION}

Combined analysis of the omics data from both PPS2 and PPS3 highlighted alterations in one-carbon metabolism and related pathways as a common effect of an increased dietary exposure to palm oil fat. Here we present a detailed overview 
Table 2. Significantly changed phosphatidylcholines, sphingomyelins, lysophosphatidylcholines, and carnitines after low-and high-fat feeding

\begin{tabular}{|c|c|c|c|c|c|c|}
\hline & \multicolumn{2}{|c|}{ Low-Fat Diet } & \multicolumn{2}{|c|}{ High-Fat Diet } & $\mathrm{FC}$ & Adjusted $P$ Value \\
\hline C5 M DC & 0.02 & 0.01 & 0.01 & 0.01 & 0.42 & 0.0170 \\
\hline SM C20:2 & 0.11 & 0.05 & 0.06 & 0.02 & 0.52 & 0.0170 \\
\hline SM C22:3 & 0.79 & 0.24 & 0.50 & 0.20 & 0.64 & 0.0225 \\
\hline PC aa C24:0 & 0.01 & 0.00 & 0.02 & 0.01 & 1.76 & 0.0181 \\
\hline $\mathrm{PC}$ aа $\mathrm{C} 30: 0$ & 0.09 & 0.03 & 0.06 & 0.02 & 0.69 & 0.0481 \\
\hline $\mathrm{PC}$ aa $\mathrm{C} 34: 3$ & 2.05 & 0.73 & 1.12 & 0.50 & 0.55 & 0.0170 \\
\hline PC aa C34:4 & 0.16 & 0.06 & 0.08 & 0.03 & 0.50 & 0.0164 \\
\hline PC aa C36:5 & 1.11 & 0.35 & 0.69 & 0.28 & 0.62 & 0.0217 \\
\hline $\mathrm{PC}$ aa $\mathrm{C} 36: 6$ & 0.07 & 0.02 & 0.05 & 0.02 & 0.64 & 0.0181 \\
\hline PC a $\mathrm{C} 38: 0$ & 0.07 & 0.01 & 0.05 & 0.02 & 0.71 & 0.0170 \\
\hline PC ae C34:0 & 0.05 & 0.01 & 0.03 & 0.01 & 0.58 & 0.0044 \\
\hline $\mathrm{PC}$ ae $\mathrm{C} 34: 1$ & 0.24 & 0.06 & 0.16 & 0.05 & 0.65 & 0.0170 \\
\hline PC ae C38:0 & 0.58 & 0.13 & 0.38 & 0.16 & 0.65 & 0.0181 \\
\hline $\mathrm{PC}$ ae $\mathrm{C} 38: 2$ & 0.12 & 0.04 & 0.07 & 0.03 & 0.64 & 0.0225 \\
\hline PC ae C40:6 & 0.13 & 0.02 & 0.09 & 0.04 & 0.73 & 0.0448 \\
\hline lysoPC a C16:1 & 0.07 & 0.03 & 0.03 & 0.01 & 0.50 & 0.0164 \\
\hline lysoPC a C28:1 & 0.04 & 0.02 & 0.08 & 0.04 & 1.99 & 0.0341 \\
\hline
\end{tabular}

Concentrations are expressed in nmol/mg protein. Low-fat and high-fat diets, diets in which $10 \%$ and $45 \%$ energy is provided by fat, respectively; C5 M DC, methylglutaryl-L-carnitine; SM, sphingomyelin; PC, phosphatidylcholine; lysoPC, lysophosphatidylcholine; aa, diacyl bond; ae, acyl-alkyl bond; FC, fold change. Cx: $n$ indicates the length of the fatty acid with $x$ carbons containing $n$ double bonds.

of the findings obtained in these studies and furthermore demonstrate convincingly that agreement in results obtained in two different laboratories is possible even if previous reports have questioned the ability to achieve this (26).

C57BL/6J mice after $12 \mathrm{wk}$ on a high-fat palm oil-based diet became obese, hyperglycemic, and insulin resistant and displayed elevated levels of plasma cholesterol and serum VLDL. Metabolite profiling of the liver samples revealed that numerous amino acids and derivatives related to one-carbon metabolism were significantly changed, highlighting this pathway as one of the main perturbations observed after the high-fat diet.

Table 3. Significantly changed liver fatty acids after 12-wk high-fat treatment

\begin{tabular}{lrrrrrr}
\hline \hline & \multicolumn{2}{c}{ Low-Fat Diet } & & \multicolumn{2}{c}{ High-Fat Diet } & \\
\cline { 2 - 3 } Fatty Acid & Mean & SD & & Mean & SD & $P$ Value \\
\hline C17:0 & 0.09 & 0.01 & & 0.08 & 0.01 & 0.020 \\
C18:0 & 7.63 & 0.81 & & 5.73 & 1.87 & 0.021 \\
C20:0 & 0.13 & 0.04 & & 0.22 & 0.05 & 0.002 \\
C23:0 & 0.04 & 0.01 & & 0.02 & 0.01 & 0.002 \\
C24:0 & 0.13 & 0.02 & & 0.08 & 0.02 & 0.000 \\
C20:1 & 0.37 & 0.16 & 0.69 & 0.28 & 0.017 \\
C24:1 & 0.17 & 0.04 & 0.08 & 0.03 & 0.000 \\
C18:1n9 & 28.00 & 4.01 & 32.66 & 3.13 & 0.028 \\
C22:1n9 & 0.03 & 0.01 & & 0.05 & 0.02 & 0.015 \\
C20:5n3 & 1.75 & 0.27 & 1.43 & 0.25 & 0.033 \\
C22:6n3 & 5.85 & 0.81 & 4.14 & 0.84 & 0.001 \\
Total MUFA & 31.60 & 4.44 & 37.26 & 5.43 & 0.045 \\
Total PUFA & 37.63 & 3.49 & 32.60 & 4.22 & 0.025 \\
\hline
\end{tabular}

Values are presented as \% total fatty acids. Low-fat and high-fat diets, diets in which $10 \%$ and $45 \%$ energy is provided by fat, respectively; MUFA, monounsaturated fatty acids; PUFA, polyunsaturated fatty acids.
Sarcosine, which can be considered the end product of methyl group turnover, and taurine for sulfur metabolism increased after high-fat feeding, whereas methionine, the precursor for these two products, decreased in concentration. Concentrations of glycine and serine as intermediates of methionine metabolism and the transsulfuration pathway decreased, while choline concentrations increased. Overall, these changes could indicate a compensation for low methionine levels with an increased remethylation from homocysteine to meet the demands for this essential amino acid with the needed methyl groups derived from choline. Since both diets contained equal amounts ( $2 \%$ by weight) of choline and mice on the low-fat diet consumed slightly more food, the higher choline level in livers of animals on the high-fat diet must therefore be of metabolic origin. No alterations in proteins involved in one-carbon metabolism were observed by the two-dimensional gel-based proteomics approach with Coomassie staining. Most probably our staining method was not sensitive enough to detect slight changes (46).

Choline may be derived from the degradation of phosphatidylcholines via betaine to deliver the methyl groups for remethylation of homocysteine with the production of dimethyl glycine and in turn sarcosine. Sarcosine levels increased on the high-fat diet, and transcript levels of two of the enzymes involved in the conversion from choline, including betainehomocysteine $S$-methyltransferase (BHMT) showed higher mRNA levels. Interestingly, high levels of BHMT have previously been demonstrated to promote hepatic apolipoprotein B and VLDL production $(41,42)$, and we also observed increased serum VLDL levels in the obese mice. Lipid transport in general and hepatic VLDL secretion need phospholipids (28), with phosphatidylcholines being the most important. Phos- 
phatidylcholines are derived in liver mainly from the Kennedy pathway. Although transcripts of the rate-limiting enzymes phosphate cytidylyltransferase 1 choline $\alpha$ and $\beta$ (Pcyt1a-b) were not determined, choline phosphotransferase 1 , which catalyzes the last step in the synthesis of phosphatidylcholines, showed increased levels. Hepatic levels of ethanolamine and phosphoethanolamine, which are precursors for phosphatidylethanolamine synthesis, were decreased, and mRNA levels of choline/ethanolaminephosphotransferase 1 (Ceptl) were also decreased. In addition, a number of the phosphatidylcholines showed decreased levels, suggesting that the hepatic ratios of the main phospholipids are altered (Supplemental Fig. S1). Although total liver phospholipid status did not reveal differences, our data strongly argue for an enhanced utilization of choline derived from phosphatidylcholine breakdown to accommodate the increased demand for remethylation of homocysteine to obtain methionine.

The crucial role of choline in hepatic fat metabolism is supported by other studies in rodents and humans. Choline deficiency alone did not lead to impaired hepatic lipid export, whereas methionine and choline deficiency in combination did (25). A recent paper showed that Pemt-null mice are resistant to diet-induced obesity and that this phenotype is reversed by administration of choline (21). Moreover, two recent human studies indicate that the susceptibility to develop a fatty liver when consuming a choline-deficient diet is associated with mutations in the Pemt promoter (7, 39). In the Hordaland Health study the relationship between plasma choline levels and cardiovascular risk factors such as obesity and glucose metabolism was assessed. Plasma choline levels were found to be positively associated with body mass index and perturbed triglyceride and glucose levels and inversely related to HDL-c (24). In a mouse study of insulin resistance, the interplay of the host-gut microflora metabolism with respect to choline metabolism was also put forward as a potential contributor to the development of insulin resistance (11).

Activity of the transsulfuration pathway is high in the liver, and the rate-limiting step is catalyzed by cystathionine $\beta$-synthase (CBS). Although a number of transcripts in this pathway were significantly downregulated, one of the metabolic end products (taurine) was increased. Most interestingly, the Cbsnull mouse phenotype is characterized by increased plasma triglyceride and VLDL levels and hyperhomocysteinemia (32) and thereby also demonstrates the close link between sulfur and methyl group metabolism and impaired lipid handling. Taurine can be used for bile acid synthesis, and since high fat intake increases the demand of bile acids for proper lipid solubilization for fat absorption in the intestine, the increased taurine may be needed in the liver for bile acid synthesis. The bile acid coenzyme A:amino acid $N$-acyltransferase (Baat) transcript was indeed increased, and this may suggest that more taurine is used for conjugation in taurocholate biosynthesis. The same may hold true for glycine needed for formation of glycocholate. In addition, bile acids in liver are known to contribute to the regulation of hepatic lipid metabolism and insulin sensitivity (44). It is possible to hypothesize that the increased taurine levels and the suggested increase in the remethylation of homocysteine to methionine may simultaneously reduce the availability of cysteine for de novo glutathione (GSH) synthesis. Indeed, we observed a significant change in the ratio of GSH and GSSG after high-fat feeding that may be related to a higher reactive oxygen species (ROS) burden and/or a reduced capacity for reduction of GSSG. In addition, protein expression level of catalase was increased in liver tissue of the animals on the high-fat diet, providing a second line of evidence for alterations in hepatic ROS handling. The presence of oxidative stress in liver after high-fat feeding has been demonstrated before (37) and is proposed to represent an important trigger for the development of insulin resistance (30). Although low glutathione levels per se could not be linked directly to hepatic triglyceride accumulation and the development of diet-induced steatohepatitis $(5,16)$, it is still possible that the altered antioxidant capacity observed here is a contributing factor to the development of insulin resistance.

In addition to alterations in the phosphocholine spectrum in liver, we also observed changes in other lipids supporting the hypothesis that an altered lipid milieu contributes to the development of insulin resistance (22). Included in these changes were altered levels of carnitines, sphingolipids, and fatty acids. Carnitine C5-M-DC was decreased in the high-fat diet group. Although specific functions of the different carnitines are not known, methylglutaryl carnitine has been previously related to insulin resistance and C5-M-DC levels in plasma of diabetic mice are increased (1). Sphingolipids that constitute a minor component of membrane lipids have also been found to change in insulin resistance and T2DM $(18,20)$. In the present study three sphingomyelin species decreased in liver and transcripts of genes involved in sphingolipid metabolism were significantly reduced as well in the obese animals. Certain saturated fatty acids and monounsaturated fatty acids were increased in the livers of animals after the high-fat diet. The changes in monounsaturated fats possibly reflect the higher dietary intake of palm oil in the high-fat diet. Interestingly, a number of n-3 polyunsaturated fatty acids and total polyunsaturated fatty acids decreased significantly, and these fatty acids are known to have a beneficial effect on insulin resistance $(12,52)$. Overall, these results provide strong evidence for a significant change in the hepatic lipid milieu that is likely contributing to the pathogenesis of insulin resistance, in agreement with recent results (22). Moreover, lipidomic analysis of liver tissue from patients with nonalcoholic fatty liver disease showed alterations in lipid homeostasis and suggests that these changes may play a role in the pathogenesis of the disease $(34,35)$.

In summary, we provide evidence for major changes in hepatic one-carbon metabolism based on metabolite, proteome, and transcriptome profiling that are associated with fat accumulation in liver following $12 \mathrm{wk}$ on a high-fat diet. Although the samples were generated in two independent feeding trials conducted at two centers with C57BL/6J mice on identical diets, the observed changes in liver metabolism were robust and very similar in characterizing a condition of insulin resistance that promotes hepatic steatosis. Changes in the metabolism of sulfur-containing amino acids and methyl groups seem to dominate the metabolic perturbations. The increased demand for phospholipids and bile acids for lipid absorption in the gut and for interorgan fat transport during high-fat feeding may initiate the changes in one-carbon metabolism in liver. The link between the Kennedy pathway and one-carbon metabolism is provided by hepatic choline concentrations that increased and hepatic methionine that decreased in liver. Secondary to the changes in one-carbon metabolism may be the alterations in ROS status and changes in the lipid milieu. These 
main findings in combination with the known alterations in lipid metabolism in human subjects should form the basis of future hypothesis-driven studies examining the role of these pathways in the development of insulin resistance and hepatic steatosis.

\section{ACKNOWLEDGMENTS}

We thank all the NuGO PPS Members for support and fruitful discussions. We acknowledge Anne Molloy for measurement of folate and homocysteine. The Biocrates Absolute IDQ Kit was kindly provided by Biocrates Life Science AG (Innsbruck, Austria).

\section{GRANTS}

This study was funded by the European Nutrigenomics Organisation, an EC-funded Network of Excellence (Grant No. FOOD-2004-506360).

\section{DISCLOSURES}

No conflicts of interest, financial or otherwise, are declared by the author(s).

\section{REFERENCES}

1. Altmaier E, Ramsay SL, Graber A, Mewes HW, Weinberger KM, Suhre K. Bioinformatics analysis of targeted metabolomics- uncovering old and new tales of diabetic mice under medication. Endocrinology 149: 3478-3489, 2008.

2. Arkan MC, Hevener AL, Greten FR, Maeda S, Li ZW, Long JM, Wynshaw-Boris A, Poli G, Olefsky J, Karin M. IKK-beta links inflammation to obesity-induced insulin resistance. Nat Med 11: 191-198, 2005.

3. Baccini M, Bachmaier EM, Biggeri A, Boekschoten MV, Bouwman FG, Brennan L, Caesar R, Cinti S, Coort SL, Crosley K, Daniel H, Drevon CA, Duthie S, Eijssen L, Elliott RM, van Erk M, Evelo C, Gibney M, Heim C, Horgan GW, Johnson IT, Kelder T, Kleemann R, Kooistra T, van Iersel MP, Mariman EC, Mayer C, McLoughlin G, Muller M, Mulholland F, van Ommen B, Polley AC, Pujos-Guillot E, Rubio-Aliaga I, Roche HM, de Roos B, Sailer M, Tonini G, Williams LM, de Wit N. The NuGO proof of principle study package: a collaborative research effort of the European Nutrigenomics Organisation. Genes Nutr 3: 147-151, 2008.

4. Bejamini Y, Hochberg Y. Controlling the false discovery rate: a practical and powerful approach to multiple testing. J R Stat Soc Ser B 57: 289-300, 1995.

5. Brandsch C, Schmidt T, Behn D, Weisze K, Muller AS, Stangl GI. Glutathione deficiency down-regulates hepatic lipogenesis in rats. Lipids Health Dis 9: 50, 2010.

6. Cai D, Yuan M, Frantz DF, Melendez PA, Hansen L, Lee J, Shoelson SE. Local and systemic insulin resistance resulting from hepatic activation of IKK-beta and NF-kappaB. Nat Med 11: 183-190, 2005.

7. da Costa KA, Kozyreva OG, Song J, Galanko JA, Fischer LM, Zeisel SH. Common genetic polymorphisms affect the human requirement for the nutrient choline. FASEB $J$ 20: 1336-1344, 2006.

8. Dai M, Wang P, Boyd AD, Kostov G, Athey B, Jones EG, Bunney WE, Myers RM, Speed TP, Akil H, Watson SJ, Meng F. Evolving gene/ transcript definitions significantly alter the interpretation of GeneChip data. Nucleic Acids Res 33: e175, 2005.

9. De Groot PJ, Reiff C, Mayer C, Muller M. NuGO contributions to GenePattern. Genes Nutr 3: 143-146, 2008.

10. Delgado TC, Barosa C, Castro MM, Geraldes CF, Bastos M, Baptista C, Fagulha A, Barros L, Mota A, Carvalheiro M, Jones JG, Merritt M. Sources of hepatic glucose production by ${ }^{2} \mathrm{H}_{2} \mathrm{O}$ ingestion and Bayesian analysis of ${ }^{2} \mathrm{H}$ glucuronide enrichment. Magn Reson Med 60: 517-523, 2008.

11. Dumas ME, Barton RH, Toye A, Cloarec O, Blancher C, Rothwell A, Fearnside J, Tatoud R, Blanc V, Lindon JC, Mitchell SC, Holmes E, McCarthy MI, Scott J, Gauguier D, Nicholson JK. Metabolic profiling reveals a contribution of gut microbiota to fatty liver phenotype in insulin-resistant mice. Proc Natl Acad Sci USA 103: 12511-12516, 2006.

12. Fedor D, Kelley DS. Prevention of insulin resistance by n-3 polyunsaturated fatty acids. Curr Opin Clin Nutr Metab Care 12: 138-146, 2009.

13. Gentleman RC, Carey VJ, Bates DM, Bolstad B, Dettling M, Dudoit S, Ellis B, Gautier L, Ge Y, Gentry J, Hornik K, Hothorn T, Huber W, Iacus S, Irizarry R, Leisch F, Li C, Maechler M, Rossini AJ, Sawitzki G, Smith C, Smyth G, Tierney L, Yang JY, Zhang J. Bioconductor: open software development for computational biology and bioinformatics. Genome Biol 5: R80, 2004.

14. Gorg A, Obermaier C, Boguth G, Harder A, Scheibe B, Wildgruber R, Weiss W. The current state of two-dimensional electrophoresis with immobilized pH gradients. Electrophoresis 21: 1037-1053, 2000.

15. Gregor MG, Hotamisligil GS. Adipocyte stress: the endoplasmic reticulum and metabolic disease. J Lipid Res 48: 1905-1914, 2007.

16. Haque JA, McMahan RS, Campbell JS, Shimizu-Albergine M, Wilson AM, Botta D, Bammler TK, Beyer RP, Montine TJ, Yeh MM, Kavanagh TJ, Fausto N. Attenuated progression of diet-induced steatohepatitis in glutathione-deficient mice. Lab Invest 90: 1704-1717, 2010.

17. Harrell FJ. Hmisc: Harrell Miscellaneous. R package version 3.7-0, 2009.

18. Hicks AA, Pramstaller PP, Johansson A, Vitart V, Rudan I, Ugocsai P, Aulchenko Y, Franklin CS, Liebisch G, Erdmann J, Jonasson I, Zorkoltseva IV, Pattaro C, Hayward C, Isaacs A, Hengstenberg C, Campbell S, Gnewuch C, Janssens AC, Kirichenko AV, Konig IR, Marroni F, Polasek O, Demirkan A, Kolcic I, Schwienbacher C, Igl W, Biloglav Z, Witteman JC, Pichler I, Zaboli G, Axenovich TI, Peters A, Schreiber S, Wichmann HE, Schunkert H, Hastie N, Oostra BA, Wild SH, Meitinger T, Gyllensten U, van Duijn CM, Wilson JF, Wright A, Schmitz G, Campbell H. Genetic determinants of circulating sphingolipid concentrations in European populations. PLoS Genet 5: e1000672, 2009.

19. Hoffler U, Hobbie K, Wilson R, Bai R, Rahman A, Malarkey D, Travlos G, Ghanayem BI. Diet-induced obesity is associated with hyperleptinemia, hyperinsulinemia, hepatic steatosis, and glomerulopathy in C57Bl/6J mice. Endocrine 36: 311-325, 2009.

20. Holland WL, Summers SA. Sphingolipids, insulin resistance, and metabolic disease: new insights from in vivo manipulation of sphingolipid metabolism. Endocr Rev 29: 381-402, 2008.

21. Jacobs RL, Zhao Y, Koonen DP, Sletten T, Su B, Lingrell S, Cao G, Peake DA, Kuo MS, Proctor SD, Kennedy BP, Dyck JR, Vance DE. Impaired de novo choline synthesis explains why phosphatidylethanolamine $\mathrm{N}$-methyltransferase-deficient mice are protected from diet-induced obesity. J Biol Chem 285: 22403-22413.

22. Kleemann R, van Erk M, Verschuren L, van den Hoek AM, Koek M, Wielinga PY, Jie A, Pellis L, Bobeldijk-Pastorova I, Kelder T, Toet K, Wopereis S, Cnubben N, Evelo C, van Ommen B, Kooistra T. Timeresolved and tissue-specific systems analysis of the pathogenesis of insulin resistance. PLoS One 5: e8817, 2010.

23. Kleemann R, Verschuren L, van Erk MJ, Nikolsky Y, Cnubben NH, Verheij ER, Smilde AK, Hendriks HF, Zadelaar S, Smith GJ, Kaznacheev V, Nikolskaya T, Melnikov A, Hurt-Camejo E, van der Greef J, van Ommen B, Kooistra T. Atherosclerosis and liver inflammation induced by increased dietary cholesterol intake: a combined transcriptomics and metabolomics analysis. Genome Biol 8: R200, 2007.

24. Konstantinova SV, Tell GS, Vollset SE, Nygard O, Bleie O, Ueland PM. Divergent associations of plasma choline and betaine with components of metabolic syndrome in middle age and elderly men and women. J Nutr 138: 914-920, 2008.

25. Larter CZ. Not all models of fatty liver are created equal: understanding mechanisms of steatosis development is important. J Gastroenterol Hepatol 22: 1353-1354, 2007.

26. Larter CZ, Yeh MM. Animal models of NASH: getting both pathology and metabolic context right. J Gastroenterol Hepatol 23: 1635-1648, 2008.

27. Leino A. Fully automated measurement of total homocysteine in plasma and serum on the Abbott IMx analyzer. Clin Chem 45: 569-571, 1999.

28. Li Z, Vance DE. Phosphatidylcholine and choline homeostasis. J Lipid Res 49: 1187-1194, 2008.

29. Lin J, Yang R, Tarr PT, Wu PH, Handschin C, Li S, Yang W, Pei L, Uldry M, Tontonoz P, Newgard CB, Spiegelman BM. Hyperlipidemic effects of dietary saturated fats mediated through PGC-1beta coactivation of SREBP. Cell 120: 261-273, 2005.

30. Matsuzawa-Nagata N, Takamura T, Ando H, Nakamura S, Kurita S, Misu H, Ota T, Yokoyama M, Honda M, Miyamoto K, Kaneko S. Increased oxidative stress precedes the onset of high-fat diet-induced insulin resistance and obesity. Metabolism 57: 1071-1077, 2008.

31. Molloy AM, Scott JM. Microbiological assay for serum, plasma, and red cell folate using cryopreserved, microtiter plate method. Methods Enzymol 281: 43-53, 1997.

32. Namekata K, Enokido Y, Ishii I, Nagai Y, Harada T, Kimura H. Abnormal lipid metabolism in cystathionine beta-synthase-deficient mice, 
an animal model for hyperhomocysteinemia. J Biol Chem 279: 5296152969, 2004.

33. Oosterveer MH, van Dijk TH, Tietge UJ, Boer T, Havinga R, Stellaard F, Groen AK, Kuipers F, Reijngoud DJ. High fat feeding induces hepatic fatty acid elongation in mice. PLoS One 4: e6066, 2009.

34. Puri P, Baillie RA, Wiest MM, Mirshahi F, Choudhury J, Cheung O, Sargeant C, Contos MJ, Sanyal AJ. A lipidomic analysis of nonalcoholic fatty liver disease. Hepatology 46: 1081-1090, 2007.

35. Puri P, Wiest MM, Cheung O, Mirshahi F, Sargeant C, Min HK, Contos MJ, Sterling RK, Fuchs M, Zhou H, Watkins SM, Sanyal AJ. The plasma lipidomic signature of nonalcoholic steatohepatitis. Hepatology 50: $1827-1838,2009$.

36. $\mathbf{R}$ Development Core Team. $R$ : A language and environment for statistical computing. Vienna. Austria: R Foundation for Statistical Computing, 2009.

37. Roberts CK, Barnard RJ, Sindhu RK, Jurczak M, Ehdaie A, Vaziri ND. Oxidative stress and dysregulation of NAD(P)H oxidase and antioxidant enzymes in diet-induced metabolic syndrome. Metabolism 55: 928 934, 2006

38. Sampath H, Miyazaki M, Dobrzyn A, Ntambi JM. Stearoyl-CoA desaturase-1 mediates the pro-lipogenic effects of dietary saturated fat. $J$ Biol Chem 282: 2483-2493, 2007.

39. Sha W, da Costa KA, Fischer LM, Milburn MV, Lawton KA, Berger A, Jia W, Zeisel SH. Metabolomic profiling can predict which humans will develop liver dysfunction when deprived of dietary choline. FASEB $J$ 24: 2962-2975, 2010

40. Smyth GK. Linear models and empirical Bayes methods for assessing differential expression in microarray experiments. Stat Appl Genet Mol Biol 3: Article3, 2004.

41. Sowden MP, Collins HL, Smith HC, Garrow TA, Sparks JD, Sparks CE. Apolipoprotein B mRNA and lipoprotein secretion are increased in McArdle RH-7777 cells by expression of betaine-homocysteine S-methyltransferase. Biochem J 341: 639-645, 1999.
42. Sparks JD, Collins HL, Chirieac DV, Cianci J, Jokinen J, Sowden MP, Galloway CA, Sparks CE. Hepatic very-low-density lipoprotein and apolipoprotein $\mathrm{B}$ production are increased following in vivo induction of betaine-homocysteine S-methyltransferase. Biochem J 395: 363-371, 2006.

43. Storey JD, Tibshirani R. Statistical significance for genomewide studies. Proc Natl Acad Sci USA 100: 9440-9445, 2003.

44. Trauner M, Claudel T, Fickert P, Moustafa T, Wagner M. Bile acids as regulators of hepatic lipid and glucose metabolism. Dig Dis 28: $220-224,2010$.

45. van Iersel MP, Kelder T, Pico AR, Hanspers K, Coort S, Conklin BR, Evelo C. Presenting and exploring biological pathways with PathVisio. BMC Bioinformatics 9: 399, 2008.

46. Westermeier R, Marouga R. Protein detection methods in proteomics research. Biosci Rep 25: 19-32, 2005.

47. Wickham H. plyr: Tools for splitting, applying and combining data. $\mathrm{R}$ package version $0.1 .9,2009$.

48. Wickham H. Reshaping data with the reshape package. J Stat Software 21: 12, 2007.

49. Winkelmann I, Nassl AM, Daniel H, Wenzel U. Proteome response in HT-29 human colorectal cancer cells to two apoptosis-inducing compounds with different mode of action. Int J Cancer 122: 2223-2232, 2008.

50. Wu Z, Irizarry R, Gentleman RC, Martinez-Murillo F, Spencer F. A model-based background adjustment for oligonucleotide expression arrays. J Am Stat Assoc 99: 909-917, 2004.

51. Xu H, Barnes GT, Yang Q, Tan G, Yang D, Chou CJ, Sole J, Nichols A, Ross JS, Tartaglia LA, Chen H. Chronic inflammation in fat plays a crucial role in the development of obesity-related insulin resistance. J Clin Invest 112: 1821-1830, 2003.

52. Zhou YE, Egeland GM, Meltzer SJ, Kubow S. The association of desaturase 9 and plasma fatty acid composition with insulin resistanceassociated factors in female adolescents. Metabolism 58: 158-166, 2009. 